\title{
Fenretinide Promotes Functional Recovery and Tissue Protection after Spinal Cord Contusion Injury in Mice
}

\author{
Rubèn López-Vales, ${ }^{1}$ Adriana Redensek, ${ }^{1}$ Thomas A. A. Skinner, ${ }^{2}$ Khizr I. Rathore, ${ }^{1}$ Nader Ghasemlou, ${ }^{1}$ \\ Gabriella Wojewodka, ${ }^{2}$ Juan DeSanctis, ${ }^{3}$ Danuta Radzioch, ${ }^{2 *}$ and Samuel David ${ }^{1 \star}$ \\ ${ }^{1}$ Center for Research in Neuroscience and ${ }^{2}$ Center for the Study of Host Resistance, Research Institute of the McGill University Health Center, McGill \\ University, Montreal, Quebec H3G 1A4, Canada, and ${ }^{3}$ Institute of Immunology, Central University of Venezuela, Caracas 1050-A, Venezuela
}

The inflammatory response is thought to contribute to secondary damage after spinal cord injury (SCI). Polyunsaturated fatty acids (PUFAs) play an important role in the onset and resolution of inflammation. Arachidonic acid (AA), an $\omega-6$ PUFA, contributes to the initiation of inflammatory responses, whereas docosahexaenoic acid (DHA), an $\omega$-3 PUFA, has antiinflammatory effects. Therefore, decreasing AA and increasing DHA levels after SCI might be expected to attenuate inflammation after SCI and promote tissue protection and functional recovery. We show here that daily oral administration of fenretinide after spinal cord contusion injury led to a significant decrease in AA and an increase in DHA levels in plasma and injured spinal cord tissue. This was accompanied by a significant reduction in tissue damage and improvement in locomotor recovery. Fenretinide also reduced the expression of proinflammatory genes and the levels of oxidative stress markers after SCI. In addition, in vitro studies demonstrated that fenretinide reduced TNF- $\alpha$ (tumor necrosis factor- $\alpha$ ) expression by reactive microglia. These results demonstrate that fenretinide treatment after SCI can reduce inflammation and tissue damage in the spinal cord and improve locomotor recovery. These beneficial effects may be mediated via the ability of fenretinide to modulate PUFA homeostasis. Since fenretinide is currently in clinical trials for the treatment of cancers, this drug might be a good candidate for the treatment of acute SCI in humans.

\section{Introduction}

Injury to the spinal cord leads to functional impairments caused by the death of neurons and glial cells, and the disruption of axonal pathways. The primary insult triggers a rapid inflammatory response locally after spinal cord injury (SCI) that contributes to secondary tissue damage mediated by proinflammatory cytokines, free radicals, eicosanoids, and other molecules (Kwon et al., 2004; Donnelly and Popovich, 2008; Popovich and Longbrake, 2008). The inflammatory response is therefore a good target for the development of therapeutic approaches to treat SCI.

Polyunsaturated fatty acids (PUFAs) play important roles in the CNS as they do in other tissues. These include production of cellular membranes and as precursors for a variety of physiologically active substances. After injury, however, PUFAs appear to be important regulators of the onset and resolution of the inflammatory response (Farooqui et al., 2007; Serhan et al., 2008).

Received Nov. 20, 2009; accepted Jan. 1, 2010.

This work was supported by grants from the Canadian Institutes of Health Research (CIHR) (S.D.,D.R.). R.L.-V. was supported by a CIHR postdoctoral fellowship, A.R. was supported by a Studentship Award from the CIHR Training Program in Neuroinflammation, and T.A.A.S. was supported by a CIHR Graduate Student Award.

${ }^{*}$ D.R. and S.D. contributed equally to this work.

Correspondence should be addressed to Dr. Samuel David, Center for Research in Neuroscience, Research Institute of the McGill University Health Center, Livingston Hall, Room L7-210, 1650 Cedar Avenue, Montreal, Quebec H3G 1A4, Canada. E-mail: sam.david@mcgill.ca.

R. López-Vales's present address: Departament de Biologia Cellular, Fisiologia i Immunologia, Institut de Neurociències, Centro de Investigación Biomédica en Red sobre Enfermedades Neurodegenerativas, Universitat Autònoma de Barcelona, 08193 Bellaterra, Spain.

DOI:10.1523/JNEUROSCI.5770-09.2010

Copyright $\odot 2010$ the authors $\quad 0270-6474 / 10 / 303220-07 \$ 15.00 / 0$
Arachidonic acid (AA), an $\omega-6$ PUFA, is metabolized by cyclooxygenases (COXs) and lipoxygenases (LOXs), giving rise to prostaglandins, thromboxanes, and leukotrienes, which are potent proinflammatory mediators (Smith and Dewitt, 1996). Administration of selective inhibitors for COX or LOX promotes neuroprotection and functional recovery after SCI (Resnick et al., 1998; Hains et al., 2001; Genovese et al., 2005). However, docosahexaenoic acid (DHA), an $\omega$-3 PUFA, has antiinflammatory properties and plays a role in the resolution of inflammation (Schwab et al., 2007; Serhan et al., 2008). In addition, DHA also has potent free radical scavenging and antioxidant properties (Endres and von Schacky, 1996; Sarsilmaz et al., 2003).

Recent studies have shown that intravenous injections of DHA attenuated functional and tissue loss after SCI in rats (King et al., 2006; Huang et al., 2007). We therefore reasoned that additional protection and functional recovery might be achieved after SCI if AA levels are decreased at the same time as DHA levels are increased. Recent work from Radzioch's group (Saeed et al., 2008; Guilbault et al., 2009) showed that fenretinide, a semisynthetic analog of retinoic acid, reduced AA but increased DHA levels in plasma in a mouse model of cystic fibrosis. We therefore assessed whether fenretinide could also modulate PUFA composition in the injured spinal cord after contusion injury and thus attenuate the inflammatory responses and functional deficits.

\section{Materials and Methods}

Spinal cord contusion injury. All surgical procedures were approved by the McGill University Animal Care Committee and followed the guidelines of the Canadian Council on Animal Care. Adult (8- to 10-week-old) 
female BALB/c mice (Charles River) were anesthetized with ketamine/ xylazine/acepromazine $(50: 5: 1 \mathrm{mg} / \mathrm{kg})$. After performing a laminectomy at the 11th thoracic vertebrae, the exposed spinal cord was contused using the Infinite Horizons Impactor device (Precision Scientific). Moderate injuries were made using a force of $50 \mathrm{kdyn}$ and tissue displacement ranging between 400 and $600 \mu \mathrm{m}$ as described previously (Ghasemlou et al., 2005).

Fenretinide preparation and treatment. Three groups of mice were given fenretinide orally, daily for $28 \mathrm{~d}$ starting at 1,6 , or $24 \mathrm{~h}$ after contusion injury. Fenretinide powder (kindly provided by Dr. Robert Smith, National Institutes of Health, Bethesda, MD) was resuspended in $95 \%$ ethanol under sterile conditions to generate a $2 \mathrm{mg} / \mathrm{ml}$ stock solution. An aliquot of this solution was mixed into a daily liquid diet of Peptamen (Nestle) at a dose of $5 \mathrm{mg} \cdot \mathrm{kg}^{-1} \cdot \mathrm{d}^{-1}$ for oral consumption. This dose was chosen based on our pervious work on the cystic fibrosis model of Pseudomonas infection in which it was found to completely correct defects in fatty acid metabolism (Guilbault et al., 2008, 2009). The suspension was protected from light and kept at $4^{\circ} \mathrm{C}$ before treatment of the mice. For the first $3 \mathrm{~d}$ after SCI, $300 \mu \mathrm{l}$ of Peptamen containing fenretinide $(5 \mathrm{mg} / \mathrm{kg})$ was administered daily by gavage. Gavage was chosen as the method of drug delivery immediately after surgery because of the loss of appetite and reduced food intake during the first $48-72 \mathrm{~h}$ after injury. The first gavage was done after a delay of 1,6 , or $24 \mathrm{~h}$. After day 3 , mice were fed the fenretinide/Peptamen mixture. At this point, mice were separated into individual cages to ascertain the amount of food and drug consumed. They were given a diet of Peptamen containing fenretinide daily in midmorning with careful monitoring of the quantity consumed by each mouse. More specifically, the daily fenretinide dose was incorporated into $12 \mathrm{ml}$ of Peptamen, which represents $80 \%$ of the daily mouse food intake, to ensure that the mice consume $100 \%$ of the daily dose of fenretinide. After the Peptamen containing fenretinide was consumed by the mice, they were given water and food ad libitum. The diet for control animals was prepared and administered in the same manner as the drug treatment; however, control animals received Peptamen containing an equivalent amount of vehicle. At the dose of fenretinide used in this study, the concentration of the drug in the blood is $0.73 \pm 0.2 \mu \mathrm{M} 4 \mathrm{~h}$ after treatment. Fenretinide has been used as an anticancer drug in several completed and ongoing clinical trials in which the desired drug concentration in the blood is $>5 \mu \mathrm{M}$ to achieve cytotoxic effects against cancer cells (Formelli et al., 2008). As mentioned above, we have evidence that blood concentration of the drug $\sim 1 \mu \mathrm{M}$ is achievable using a dose of $5 \mathrm{mg} \cdot \mathrm{kg}^{-1} \cdot \mathrm{d}^{-1}$ used in the present study, which is sufficient for normalization of fatty acid imbalance and inhibition of inflammatory gene expression.

Lipid analysis. To assess the plasma kinetics, blood samples were taken from the saphenous vein at day $0,1,3,7,11$, and $21 \mathrm{dpi}$. On day 28 , blood samples were obtained by intracardiac puncture. All blood samples were mixed with $10 \mu \mathrm{l}$ of EDTA and centrifuged at $350 \times g$ for $7 \mathrm{~min}$ at $4^{\circ} \mathrm{C}$. The plasma was then removed and lipids were extracted with chloroform-methanol $(2: 1 \mathrm{v} / \mathrm{v})$ containing $1 \mathrm{~mm}$ BHA (butylated hydroxyanisole), as previously described (Folch et al., 1957). The lipid fractions were dried under nitrogen and resuspended in heptane (De Sanctis, 1991). Phosphate (Pi) concentration in each sample was assessed using PiBlue Phosphate Assay kit (Bioassay Systems). Phospholipids were identified by thin-layer chromatography extraction. Diazomethane was used to esterify the released fatty acids and the esters were identified by gas chromatography/mass spectrometry (Hewlett Packard 5880A; WCOT capillary column; Supelco-10) using commercial standards (Sigma-Aldrich).

Lipid peroxidation was measured fluorometrically as previously described (Niehaus and Samuelsson, 1968; Ohkawa et al., 1979) using 2-thiobarbituric acid-reactive substances (TBARS) as surrogate for malonyldealdehyde (MDA), the end product of lipid peroxidation. To normalize the values of TBARS, protein concentration was assessed by the bicinchoninic acid assay (Pierce Biotechnology). The results are expressed in nanomoles of TBARS per milligram of protein, which reflects the levels of MDA in the samples as well as any other thiobarbituric acid-reactive substances, if any should have arisen during the assay (Lykkesfeldt, 2007) Total levels as well as phospholipid-bound levels of
DHA and AA, MDA, and nitrotyrosine were assessed in both plasma and spinal cord samples.

Nitrotyrosine analysis. The total amount of 3-nitrotyrosine was determined by ELISA as previously described (Montes de Oca et al., 2008) using previously characterized antibodies (Ye et al., 1996). Antibodies (mouse IgG monoclonal, polyclonal against nitrotyrosine, and polyclonal goat anti-rabbit IgG-peroxidase) were from Millipore. The quantification of nitrotyrosine was performed using a standard curve with known concentrations of nitrotyrosine from chemically modified bovine serum albumin. The sensitivity of the assay was $50 \mathrm{pg} / \mathrm{ml}$.

$m R N A$ analysis. A $5 \mathrm{~mm}$ length of the spinal cord containing the lesion site was harvested at $1 \mathrm{~d}$ postinjury (dpi) from experimental and control groups. Three spinal cords were pooled and RNA was extracted using RNeasy Lipid Tissue kit (QIAGEN). PCR amplification was performed with specific primers for mouse interleukin- $1 \beta$ (IL-1 $\beta$ ), tumor necrosis factor $\alpha$ (TNF- $\alpha$ ), monocyte chemoattractant protein-1 (MCP-1), and inducible nitric oxide synthase (iNOS) to screen genes modulated by fenretinide. PPIA (peptidylprolyl isomerase A) was used as a control to ensure equal cDNA samples for PCR amplification. Those genes showing at least a $30 \%$ change after fenretinide treatment were further analyzed by quantitative real-time PCR (Q-PCR). Three separate experiments were done with spinal cords from three different mice. GAPDH was used as a housekeeping gene. The amount of cDNA was calculated based on the threshold cycle $\left(C_{\mathrm{T}}\right)$ value and was standardized by the amount of housekeeping gene using the $2^{-\Delta \Delta C_{\mathrm{T}}}$ method (Livak and Schmittgen, 2001).

Functional assessment. Locomotor recovery was evaluated in an openfield test using the nine-point Basso Mouse Scale (BMS) (Basso et al., 2006), which was specifically developed for locomotor testing after contusion injuries in mice. The BMS analysis of hindlimb movements and coordination was performed by two independent assessors who were trained in the Basso laboratory at Ohio State University, and the consensus score was taken. The final score is presented as mean \pm SEM. The 11-point BMS subscores, which evaluate finer aspects of locomotor control, were also assessed. Control animals for the 6 and $24 \mathrm{~h}$ delayed treatment groups showed no difference in the BMS scores and were thus pooled.

Histological analysis. At $28 \mathrm{~d}$ after lesion, mice were perfused with $4 \%$ paraformaldehyde in $0.1 \mathrm{~m}$ phosphate buffer (PB). A $5 \mathrm{~mm}$ length of the spinal cord containing the lesion site was removed, cryoprotected with $30 \%$ sucrose in $0.1 \mathrm{M} \mathrm{PB}$, and cut in serial sections ( $16 \mu \mathrm{m}$ thick). Serial tissue sections were immunostained using rat monoclonal antibodies against GFAP (1:400; Zymed Laboratories), mouse monoclonal antibodies against NeuN (1:400; Millipore Bioscience Research Reagents), chicken polyclonal antibodies against neurofilament (NF) (1:2000; Millipore Bioscience Research Reagents), and rabbit polyclonal antibodies against serotonin (5-HT) (1:5000; Sigma-Aldrich). Tissue sections were viewed with an Axioskop 2 Plus microscope (Zeiss), and images were captured using a QImaging Retiga 1300 camera, and quantification was done using BioQuant Nova Prime image analysis system (BioQuant Image Analysis). Tissue sparing was calculated by delineating the GFAPstained areas (GFAP-positive tissue), and neuronal survival was assessed by counting the NeuN-positive cells in the ventral horn. Neuronal counts in the ventral horn were also done on tissue stained with cresyl violet. Assessment of serotonergic fiber sparing was performed by calculating the area occupied by serotonergic axons in the ventral horn of spinal cord sections taken at a distance of $1 \mathrm{~mm}$ caudal to the lesion epicenter. Axonal sparing was assessed by calculating the area occupied by antineurofilament staining in cross sections of the spinal cord at the lesion epicenter.

Microglia activation in vitro. Mouse microglial cultures were prepared as described previously (Saura et al., 2003). Briefly, confluent mixed glial cultures prepared from the neonatal cerebral cortex were treated for 30 min with trypsin $(0.08 \%)$ in the presence of $0.25 \mathrm{~mm}$ EDTA and $0.5 \mathrm{~mm}$ $\mathrm{Ca}^{2+}$. This treatment results in the detachment of an intact layer of cells containing virtually all the astrocytes and leaves a population of firmly attached cells identified as $>98 \%$ microglia as assessed by counts of CD11b-immunoreactive cells (Saura et al., 2003). These microglial cells were stimulated with lipopolysaccharide (LPS) (10 ng/ml) in DMEM/ F12 culture medium containing $1 \%$ penicillin/streptomycin and $1 \%$ vi- 

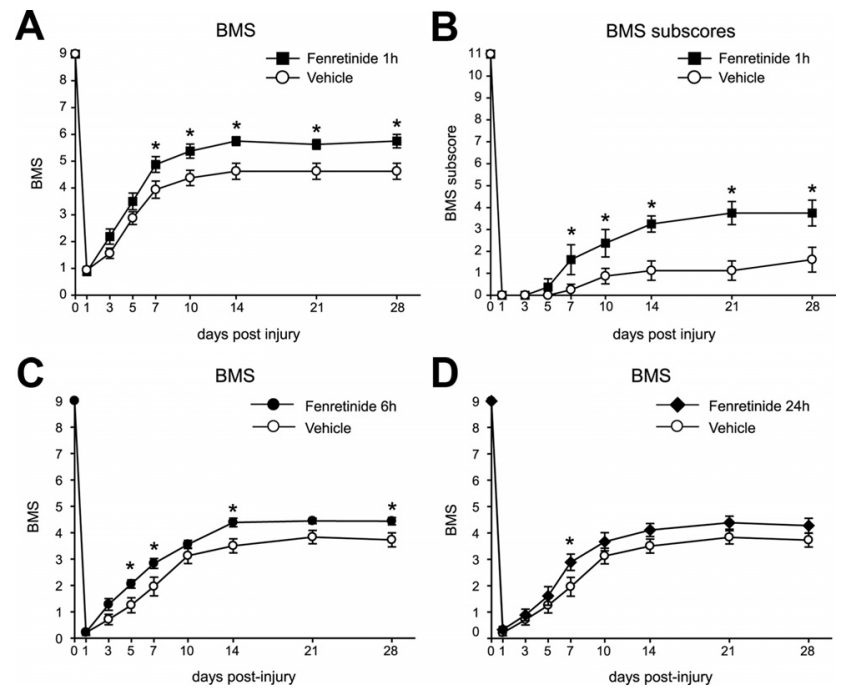

Figure 1. $\quad A, B$, Time course of locomotor recovery in mice treated with fenretinide starting $1 \mathrm{~h}$ after $\mathrm{SCl}$. Evaluation was done using the 9-point BMS $(\boldsymbol{A})$ and the 11-point BMS subscores $(B)$, which evaluate finer aspects of locomotor control. Note that animals treated with fenretinide show significantly enhanced locomotor recovery starting from day 7 after $\mathrm{SCl}$ in the BMS scores and in the BMS subscores ( ${ }^{*} p<0.05 ; n=8$ for each group). C, BMS scores of locomotor skills show that fenretinide treatment started after a delay of $6 \mathrm{~h}$ after $\mathrm{SCl}$ also promoted significant improvement in locomotor recovery (fenretinide group, $n=9$; vehicle group, $n=$ 11). $\boldsymbol{D}$, After a $24 \mathrm{~h}$ delay in the start of treatment, there was a significant improvement in locomotor score early after injury ( 1 week), but this effect was not sustained (fenretinide group, $n=9$; vehicle group, $n=11)\left({ }^{*} p<0.05\right)$. Error bars indicate SEM.

tamins for $6 \mathrm{~h}$. The LPS concentration and incubation time was based on previous experiments used to optimize conditions for measuring TNF- $\alpha$ release from activated microglia. Treatment with fenretinide $(0.625$ or $1.25 \mu \mathrm{M}$ in DMEM/F12) was initiated $18 \mathrm{~h}$ before LPS stimulation, and continued together with LPS stimulation. The protocol for fenretinide treatment was based on previous studies on toxicity and reduction of TNF- $\alpha$ levels in macrophages (D. Radzioch, unpublished data). The amount of TNF- $\alpha$ released in $50 \mu$ l of the conditioned medium was determined by ELISA.

Statistical analyses. Data are shown as mean \pm SEM. Statistical analyses were performed by using Student's $t$ test or two-way repeated-measures ANOVA (RM-ANOVA) with post hoc Tukey's test for multiple comparisons. Differences were considered significant at $p<0.05$.

\section{Results}

\section{Fenretinide enhances functional recovery after SCI}

Compared with the vehicle-treated mice, those treated with fenretinide starting $1 \mathrm{~h}$ after SCI showed significant improvement in locomotor recovery (Fig. $1 A)\left({ }^{*} p<0.05\right.$; two-way RM-ANOVA, Tukey's post hoc test; $n=8$ for both groups). Post hoc analysis revealed significant differences in BMS score starting at day 7 after injury and remaining significantly enhanced for the 4 week duration of the study. At $28 \mathrm{dpi}$, vehicle-treated mice were able to step occasionally or frequently but without coordination (score, 4.6). In contrast, mice treated with fenretinide displayed frequent or consistent plantar stepping with some coordination and more parallel paw position (score, 5.8). In addition, fine locomotor control assessed by the BMS subscores also showed a significant improvement in mice treated with fenretinide from days 7 to 28 after SCI. At $28 \mathrm{dpi}$, mice given with fenretinide had a mean subscore that is 2.2 points higher than that of vehicle-treated mice (Fig. $1 B$ ). We also assessed the effectiveness of delaying the onset of fenretinide treatment beyond $1 \mathrm{~h}$ after SCI. Two additional groups were tested in which treatment was started 6 or $24 \mathrm{~h}$ after SCI. The $6 \mathrm{~h}$ delay group also showed significant improvement in locomotor recovery compared with vehicle-treated mice (Fig. 1C) $(n=9$ for fenretinide-treated and $n=11$ for vehicle-treated groups). Post hoc analysis revealed significant differences in BMS score starting at day 5 after injury and remaining significantly enhanced at day 28. This effect was reduced when treatment was initiated $24 \mathrm{~h}$ after SCI. Post hoc analysis of this group showed a significant difference only at $7 \mathrm{dpi}$ (Fig. 1D) $(n=9$ for fenretinide-treated and $n=11$ for vehicle-treated groups). Whether the $24 \mathrm{~h}$ delayed treatment would be more effective at higher doses of fenretinide is not known at present. Additional histological, lipid, and immunochemical analyses of the effects of fenretinide were performed in the group of mice in which treatment was started $1 \mathrm{~h}$ after SCI.

\section{Fenretinide ameliorates tissue damage after SCI}

We next examined whether the improvement in motor function mediated by fenretinide treatment started $1 \mathrm{~h}$ after SCI was associated with a reduction in secondary damage in the spinal cord. Histological sections of spinal cord stained for GFAP showed that fenretinide treatment reduced tissue loss by $\sim 20 \%$ ( $p<0.001$; $n=8)$. Prevention of tissue loss achieved after fenretinide treatment was evident at the lesion epicenter and in adjacent areas, for a total rostrocaudal distance of $1000 \mu \mathrm{m}$ (Fig. $2 A-C)\left({ }^{\star} p<0.05\right.$, two-way RM-ANOVA, Tukey's post hoc test).

We also assessed whether fenretinide attenuated neuronal loss in the ventral horns after SCI. This was assessed in tissue sections stained with anti-NeuN. Mice treated with fenretinide showed a significantly greater numbers of neurons compared with vehicletreated mice at 300 and $500 \mu \mathrm{m}$ rostral and $500 \mu \mathrm{m}$ caudal of the lesion epicenter compared with vehicle-treated lesioned control mice (Fig. $2 D-F)\left(n=8\right.$; ${ }^{\star} p<0.05$, two-way RM-ANOVA, Tukey's post hoc test). Quantification of cresyl violet-stained tissue sections showed similar results (supplemental Fig. 1, available at www.jneurosci.org as supplemental material).

We also assessed whether the improved tissue sparing in mice treated with fenretinide also resulted in greater preservation of serotonergic fibers caudal to the site of the injury. Serotonergic axons play an important role in locomotor control (Ribotta et al., 2000). Spinal cord sections stained for serotonin showed that fenretinide treatment resulted in $\sim 60 \%$ greater sparing of serotonergic fibers in the ventral horn $1 \mathrm{~mm}$ caudal to the lesion epicenter compared with vehicle-treated controls (Fig. 2G-I) $\left({ }^{\star} p<0.01 ; n=8\right)$. Spinal cord sections from the lesion epicenter were also immunostained for neurofilament. Greater axonal sparing was observed at the epicenter of the lesion after fenretinide treatment compared with vehicle-treated controls (Fig. 3) $(n=8)$ (fenretinide, $11.02 \pm 1.07 \times 10^{5} \mu \mathrm{m}^{2}$, vs vehicle, $6.57 \pm$ $0.85 \times 10^{5} \mu \mathrm{m}^{2} ; p=0.006, t$ test $)$.

\section{Fenretinide modulates AA and DHA levels after SCI}

The plasma levels of AA, a proinflammatory fatty acid, are rapidly increased as early as $1 \mathrm{~d}$ after SCI from 35 to $45 \mathrm{nmol} / \mathrm{mg}$ protein $(p<0.05)$. The levels remained plateaued at the elevated level until day 28 ( $p<0.001 ; n=5$ for each group) (Fig. $4 A$ ). In contrast, the plasma levels of DHA, an antiinflammatory and protective fatty acid, are transiently increased at day 1 after SCI and then sharply decreased at day 3 after injury and maintained at this low level for the $28 \mathrm{~d}$ duration of the study $(p<0.01)$ (Fig. $4 B)(n=5$ for each group). Interestingly, treatment with fenretinide resulted in a statistically significant reduction in the plasma levels of AA starting at $1 \mathrm{dpi}$ and continued to decrease even further through the $28 \mathrm{~d}$ duration of the study (Fig. $4 A$ ). The effect of fenretinide treatment on AA levels was accompanied by 

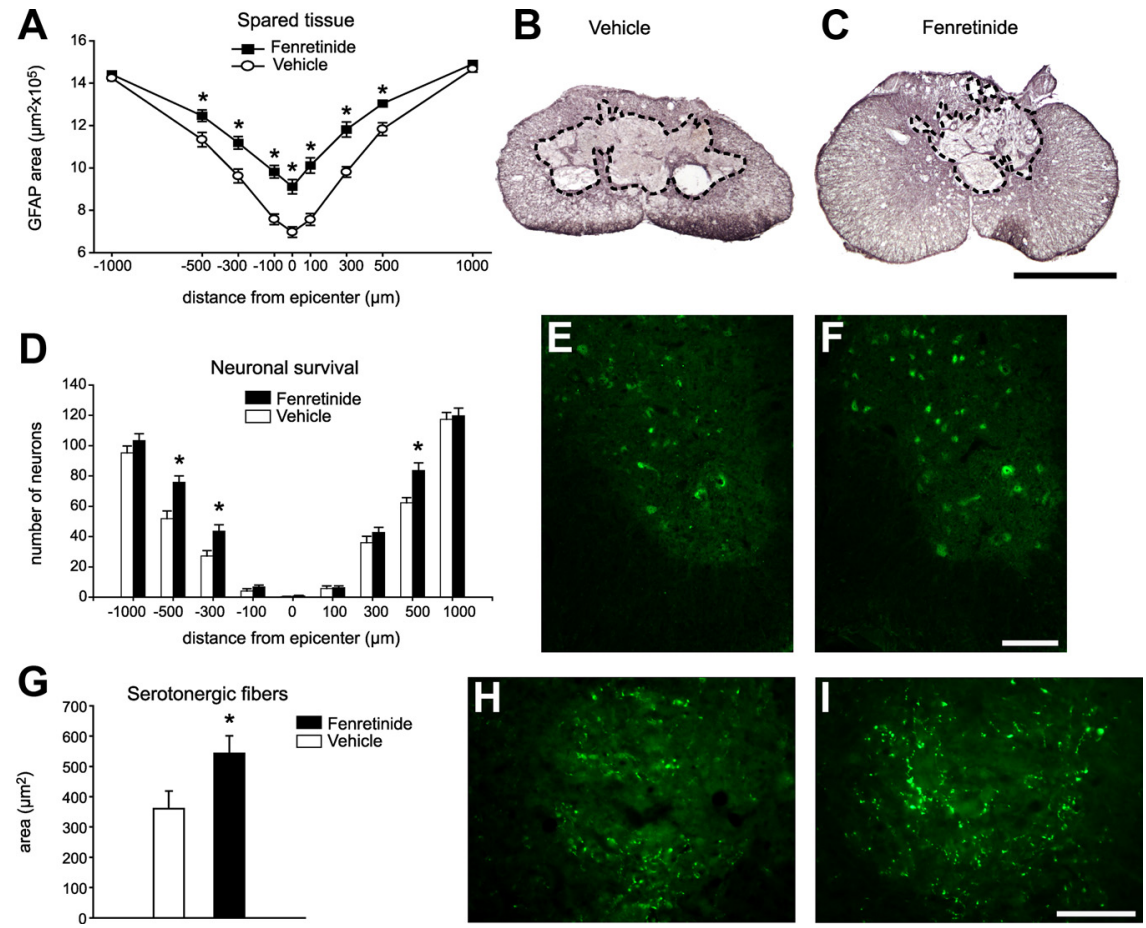

Figure 2. A, Quantification of histological sections stained with anti-GFAP at different distances from the lesion epicenter (0) show that tissue sparing was significant improved at the epicenter and areas rostral and caudal in mice treated with fenretinide $\left({ }^{*} p<0.05\right) . \boldsymbol{B}, \boldsymbol{C}$, Representative micrographs showing GFAP immunostaining at the epicenter of the injury in vehicle $(\boldsymbol{B})$ - and fenretinide ( $(\boldsymbol{C}$-treated mice at $28 \mathrm{dpi}$. Note the greater tissue sparing in mice treated with fenretinide. $\boldsymbol{D}$, Graph showing that mice treated with fenretinide have greater neuron survival at distances of 300 and $500 \mu \mathrm{m}$ rostral and $500 \mu \mathrm{m}$ caudal to the lesion epicenter $\left({ }^{*} p<0.05\right.$ ). Quantification done on tissue sections stained with NeuN. $\boldsymbol{E}, \boldsymbol{F}$, Micrographs showing NeuN staining of neurons in the ventral horn $500 \mu \mathrm{m}$ rostral to the lesion epicenter in mice treated with vehicle $(\boldsymbol{E})$ and fenretinide $(\boldsymbol{F})$ at $28 \mathrm{dpi}$. Note the marked increased in neuronal profiles in mice treated with fenretinide. $\mathbf{G}$, Mice treated with fenretinide display significantly greater serotonergic innervation in the ventral horns $1 \mathrm{~mm}$ caudal to the lesion epicenter $\left({ }^{*} p<0.01\right) . \boldsymbol{H}, \boldsymbol{I}$, Representative micrographs showing 5 -HT-immunoreactive fibers in the ventral horn at a distance $1000 \mu \mathrm{m}$ caudal to the injury site in vehicle $(\boldsymbol{H})$ - and fenretinide $(\boldsymbol{I})$-treated mice. A marked increased in serotonergic fibers is seen in the ventral horns of mice treated with fenretinide compared with vehicle-treated injured mice ( $n=8$ for each group). Scale bars: $B, C, 500 \mu \mathrm{m}, \boldsymbol{E}, \boldsymbol{F}, \boldsymbol{H}, \mathbf{I}, 100 \mu \mathrm{m}$. Error bars indicate SEM.
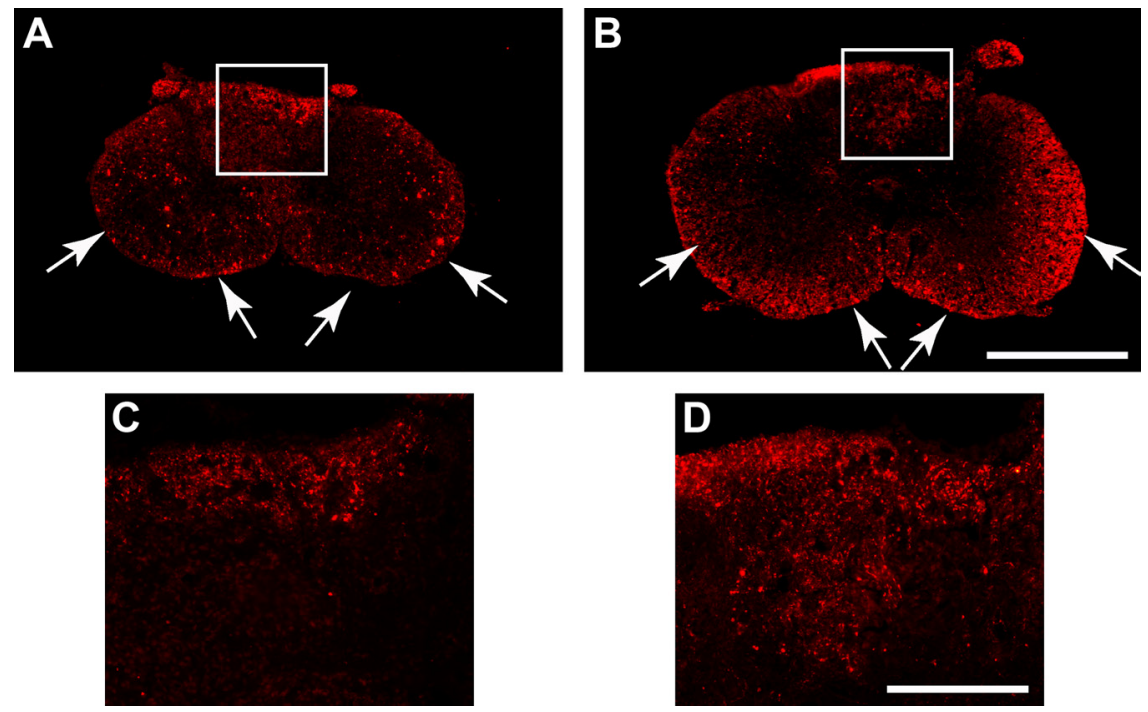

Figure 3. Representative micrographs showing NF immunostaining at the epicenter of the injury in vehicle $(\boldsymbol{A})$ - and fenretinide $(\boldsymbol{B})$-treated mice at $28 \mathrm{dpi}$. Note the greater axonal sparing in mice treated with fenretinide (arrows). The area outlined in the box is shown in higher magnification in $\boldsymbol{C}$ and $\boldsymbol{D}$. Higher magnification images show greater sparing of axons in the dorsal white matter after fenretinide treatment $(\boldsymbol{D})$ compared with vehicle-treated controls (C). Scale bars: $\boldsymbol{B}, 500 \mu \mathrm{m} ; \boldsymbol{D}, 100 \mu \mathrm{m}$. a concomitant increase in DHA levels in the plasma that were significantly higher than the vehicle-treated SCI mice from days 3 to 28 , as well as above naive uninjured control levels for the entire duration of the study (Fig. $4 \mathrm{~B}$ ).

We also assessed whether fenretinide could modulate the AA and DHA levels in the injured spinal cord tissue at 3 dpi (i.e., the first time point when DHA levels in plasma were significantly modulated by treatment with fenretinide). Interestingly, a similar decrease in AA $(p<0.05)$ and increase in DHA $(p<0.001 ; n=3$ for each group) were detected in injured spinal cord tissue (Fig. 4C,D).

Fenretinide reduces the expression of proinflammatory mediators and attenuates oxidative stress after SCI Since AA is a potent inflammatory trigger, we assessed whether fenretinide reduces the inflammatory response by assessing the mRNA levels of several proinflammatory mediators. Reverse transcription (RT)-PCR analyses showed that IL- $1 \beta$, TNF- $\alpha$, MCP-1, and iNOS mRNA levels were reduced at least $30 \%$ in the spinal cord of mice treated with fenretinide compared with the vehicle mice (Fig. 5A). Additional analyses by quantitative realtime PCR revealed that fenretinide treatment significantly reduced the mRNA levels for TNF- $\alpha$ and iNOS but not for IL- $1 \beta$ or MCP-1 (Fig. $5 B)(n=3)$.

Since DHA has antioxidant properties, we also studied whether fenretinide reduced oxidative stress after SCI by assessing MDA, a product of lipid peroxidation, and nitrotyrosine, an indicator of damage induced by nitric oxide (NO). Results obtained from samples harvested at $3 \mathrm{dpi}$, a time point at which DHA levels in the spinal were significantly increased after injury, showed that levels of MDA (Fig. 5C) ( $n=3$ for each group) and nitrotyrosine (Fig. 5D) ( $n=3$ for each group) were decreased by twofold in mice treated with fenretinide.

\section{Fenretinide attenuates}

microglial activation

Fenretinide reduced TNF- $\alpha$ expression after SCI, suggesting that the drug might modulate the inflammatory response. This can be explained, in part, by a reduction in AA levels. However, since fenretinide is an analog of retinoic acid and reactive microglia expresses its receptors after SCI (Mey et al., 2005), we examined whether fenretinide could also exert a direct effect on microglial cells. To assess this, we activated microglial cells in vitro 

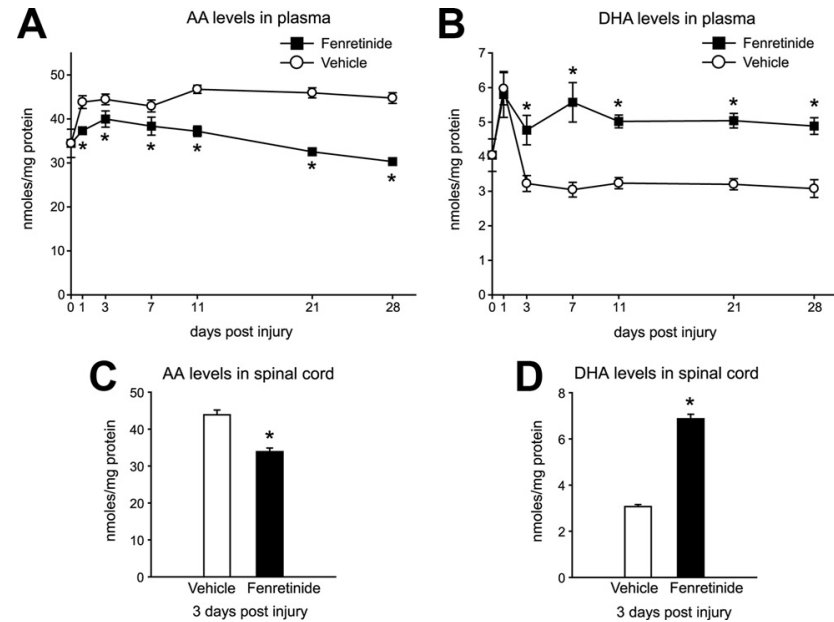

Figure 4. Quantification of $\mathrm{AA}$ and $\mathrm{DHA}$ levels in plasma and spinal cord tissue after $\mathrm{SCl}$. $\boldsymbol{A}$ Treatment with fenretinide led to a significant reduction in plasma AA levels compared with vehicle-treated mice from days 1 to 28 after $\mathrm{SCI}(n=5)$. $\boldsymbol{B}$, DHA levels in plasma were significantly higher from 3 to $28 \mathrm{dpi}$ in mice treated with fenretinide $(n=5)$. Treatment with fenretinide also caused a significant decrease in $A A(C)$ and a significant increase in DHA $(\boldsymbol{D})$ in spinal cord tissue taken $3 \mathrm{~d}$ after $\mathrm{SCl}(n=3)\left({ }^{*} p<0.05\right)$. Error bars indicate SEM.
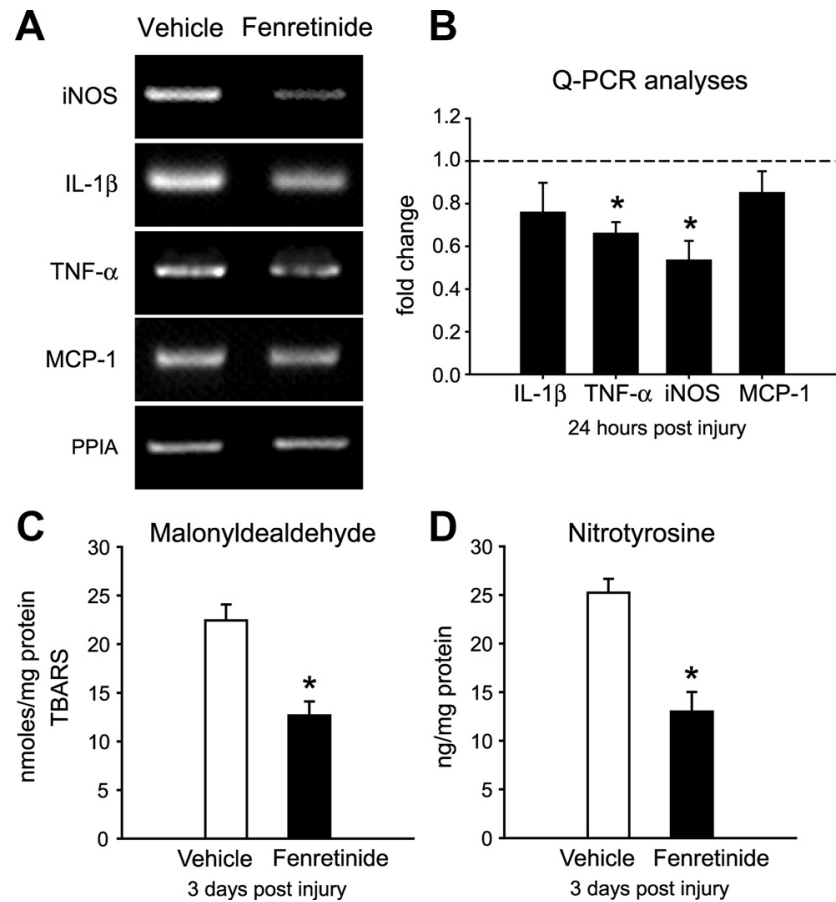

Figure 5. $\quad \boldsymbol{A}, \boldsymbol{B}$, The mRNA expression of iNOS, IL- $1 \beta$, TNF- $\alpha$, and MCP- 1 by RT-PCR $(\boldsymbol{A})$ and $Q-P C R(B)$ at 24 h after $S C l$. Quantitative real-time $P C R$ analyses revealed that mice treated with fenretinide had a significant reduction in the mRNA expression of TNF- $\alpha$ and iNOS compared with vehicle-treated mice $\left({ }^{*} p<0.05\right)$. C, $\boldsymbol{D}$, Spinal cords from mice treated with fenretinide also showed a significant reduction in the levels of MDA $(\boldsymbol{C})$ and 3-nitrotyrosine $(\boldsymbol{D})$ at $3 \mathrm{~d}$ after $\mathrm{SCl}\left({ }^{*} p<0.01 ; n=3\right)$. Error bars indicate SEM.

by the addition of LPS (10 ng/ml) and determined whether fenretinide was able to reduce the release of TNF- $\alpha$ into the culture supernatant. ELISA results from the supernatants obtained from microglial cells stimulated with LPS showed a 20 and $40 \%$ reduction in the protein levels of TNF- $\alpha$ when treated with 0.625 and $1.25 \mu \mathrm{M}$ fenretinide, respectively (Fig. 6) ( $n=3$ for each group). These doses of fenretinide did not have any toxic effects on the cells based on cell viability and cell detachment. These results

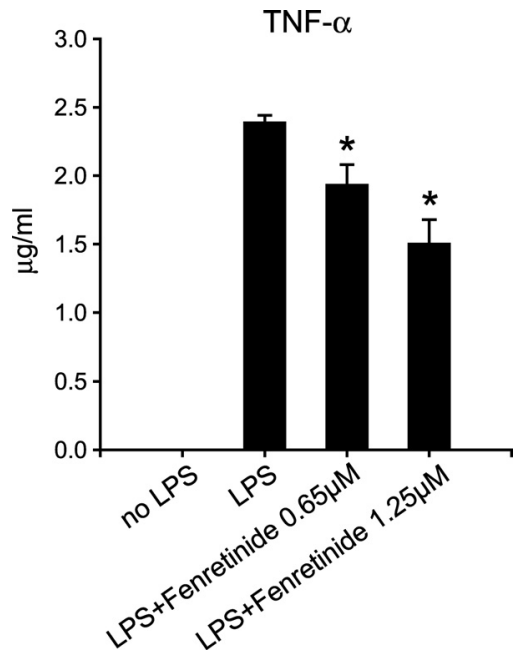

Figure 6. Effects of fenretinide treatment on TNF- $\alpha$ release from microglial cell cultures stimulated with LPS (10 ng/ml). Fenretinide induced a significant reduction in TNF- $\alpha$ release from activated microglia $\left({ }^{*} p<0.05 ; n=3\right)$. Error bars indicate SEM.

provided direct evidence that fenretinide reduces microglial activation. We also observed similar results on activated bone marrow-derived macrophages (data not shown).

\section{Discussion}

The present study provides evidence that fenretinide has a beneficial effect in the treatment of acute SCI. We show that daily administration of fenretinide starting $1 \mathrm{~h}$ after SCI results in significant enhancement of locomotor recovery, greater sparing of tissue, serotonergic fibers caudal to the lesion, and of ventral motoneuron compared with vehicle-treated animals. In searching for the underlying mechanisms, we observed that fenretinide modulates PUFA levels in the plasma and spinal cord after SCI, decreasing AA, a proinflammatory fatty acid, and increasing DHA, a protective antiinflammatory and prosurvival fatty acid. Fenretinide treatment also leads to a reduction in the expression of certain proinflammatory mediators, such as TNF- $\alpha$ and iNOS, and attenuation of oxidative stress after SCI. Fenretinide also reduces the release of TNF- $\alpha$ from activated microglial cells in vitro. Furthermore, fenretinide was also effective in promoting locomotor recovery when treatment was delayed $6 \mathrm{~h}$ after SCI.

Fenretinide is a semisynthetic analog of retinoic acid, mostly used as a potential therapeutic agent for certain types of cancer because of its antitumoral effects (Torrisi and Decensi, 2000; Malone et al., 2003). Recent studies, however, showed that fenretinide can modulate lipid homeostasis in an experimental model of cystic fibrosis, specifically of ceramides and PUFAs (Guilbault et al., 2008, 2009; Saeed et al., 2008). In agreement with these studies, we now demonstrate that fenretinide also modulates PUFA in plasma and spinal cord after SCI in mice.

Polyunsaturated fatty acids play an important role in the onset and resolution of inflammation. $\omega-6$ PUFAs, such as AA, contribute to the onset of inflammation, including that seen after SCI (Resnick et al., 1998; Kwon et al., 2004; Jones et al., 2005). AA is metabolized by LOX and COX enzymes, which produce eicosanoids, a collection of leukotrienes, prostaglandins, and thromboxanes that mediate inflammation by enhancing vascular permeability, increasing local blood flow and infiltration of leukocytes, and inducing the production of proinflammatory cytokines such as TNF- $\alpha$ and IL-1 $\beta$ (Caughey et al., 1997; Murakami et al., 1997; Brown et al., 2003; Rocha et al., 2003; Jones et al., 
2005). Blocking the synthesis of AA-derived metabolites by using nonsteroidal antiinflammatory drugs or selective inhibitors for COX-2 or LOX-5 ameliorates tissue damage in various types of CNS insults, including SCI (Hains et al., 2001; Genovese et al., 2005). Furthermore, administration of AA after SCI in rats increased tissue damage and functional loss, demonstrating its detrimental effects (King et al., 2006). In the present study, we show that fenretinide significantly reduces AA levels in plasma and in the spinal cord parenchyma after SCI, suggesting that part of the beneficial effects of fenretinide might be attributable to the reduction in AA levels.

Contrary to the $\omega$ - 6 PUFA, $\omega-3$ PUFAs, such as DHA, are potent antiinflammatory mediators. Metabolites generated from DHA, such as neuroprotectin D1 and resolvin D1, play a crucial role in the resolution of the inflammatory response (Schwab et al., 2007; Serhan et al., 2008). A single administration of DHA 30 min after SCI promoted tissue sparing and functional recovery in rats (King et al., 2006). However, additional enhancement of the functional and histological outcome was achieved when the initial injection of DHA was followed with a diet enriched in DHA, suggesting prolonged increase in DHA levels after SCI is required for greater protection (Huang et al., 2007). We now show that fenretinide treatment after SCI significantly increases the levels of DHA in plasma and spinal cord tissue. Interestingly, the fenretinide-induced increase in DHA levels in plasma was maintained for the $28 \mathrm{~d}$ duration of the study. Therefore, the protective effect of fenretinide after SCI is not only likely to be mediated by a decrease in AA levels but also by a prolonged increase in DHA levels. These results provide strong evidence that oral administration of fenretinide can alter the levels of AA and DHA after SCI and that modulation of these PUFA levels could lead to neuroprotection and locomotor recovery.

The two fatty acids, AA and DHA, have antagonistic effects on the inflammatory response, turning it on and off, respectively. Interestingly, we also observed that fenretinide treatment reduced the mRNA levels of some proinflammatory mediators, such as TNF- $\alpha$ and iNOS, in the injured spinal cord. Immune cells mediate toxic effects in SCI, in part by releasing free radicals, which cause oxidative damage to lipids, proteins, and DNA causing cell death (Floyd and Carney, 1992; Kwon et al., 2004; Jones et al., 2005). Previous work has shown that administration of AA increased inflammation and, subsequently, oxidative stress after SCI in rats (King et al., 2006), whereas DHA showed opposite effects (King et al., 2006; Huang et al., 2007). Reduction in oxidative stress by DHA is attributable, in part, to the amelioration of the inflammatory response but also to its antioxidant features (Endres and von Schacky, 1996; Sarsilmaz et al., 2003). In the present study, we observed that levels of MDA and 3-nitrotyrosine, two markers of oxidative stress, were significantly lower in spinal cords of animals treated with fenretinide. Interestingly, fenretinide also caused reduction of iNOS expression by twofold in spinal cord at $1 \mathrm{dpi}$, suggesting that the reduction in the oxidative stress by fenretinide is probably caused by both a reduction in the expression of enzymes that generate free radicals such as iNOS and the antioxidant properties of DHA. Oxidative stress (Hains et al., 2001) causes neuronal cell death after SCI (Hall and Braughler, 1986; Xu et al., 2005). Importantly, fenretinide significantly increased the survival of neurons in areas adjacent to the epicenter of the lesion.

Previous studies have shown that several indicators of oxidative stress (gp91 ${ }^{\text {Phox }}$, iNOS), lipid peroxidation (4-hydroxynonenal, TBARS), and free radical-mediated protein damage (nitrotyrosine formation) reach their peak by $6 \mathrm{~h}$ after SCI in rodents
(Bao et al., 2004, 2005). Furthermore, TNF- $\alpha$, a proinflammatory cytokine, which has been shown to play a detrimental role in SCI (Genovese et al., 2006, 2008; Ferguson et al., 2008), shows a peak of mRNA expression $1 \mathrm{~h}$ after SCI and increased protein expression 6-12 h after injury (Yang et al., 2004, 2005; Pineau and Lacroix, 2007). These data suggest that free radical-mediated lipid and protein damage is substantially underway as early as $6 \mathrm{~h}$ after SCI. Interestingly, the beneficial effects of delayed fenretinide treatment correlates well with the timing of the peak of oxidative stress and levels of proinflammatory cytokine. Fenretinide significantly improves recovery after SCI when the treatment is given within 1-6 h after SCI. At the single drug concentration used in this study, it was not effective when delayed by $24 \mathrm{~h}$ after SCI. Whether higher concentrations of the drug will be effective after delays of $24 \mathrm{~h}$ or longer will need to be examined in future work. These data therefore suggest that fenretinide via its ability to reciprocally increase protective fatty acids (DHA) while reducing the levels of harmful fatty acids (AA) could play a role in modulating the oxidative and proinflammatory state within the first $6 \mathrm{~h}$ after injury.

Several lines of evidence suggest that retinoic acid exerts an antiinflammatory effect and attenuates the production of inflammatory mediators such as TNF- $\alpha$ in various cell types in peripheral tissues, in addition to its crucial role in the regulation of cell proliferation and differentiation (Mehta et al., 1994; Datta et al., 2001). After SCI, activated microglia express the retinoic acid receptor (Mey et al., 2005). Studies in vitro have shown that retinoic acid mediates antiinflammatory effects on microglia cells, reducing the release of TNF- $\alpha$ (Dheen et al., 2005). Interestingly, we also found that fenretinide reduced by $\sim 40 \%$ the release of TNF- $\alpha$ by microglial cells in vitro, providing direct evidence that fenretinide may reduce inflammation not only by regulating PUFA homeostasis but also by modulating the responses of reactive microglia.

Blocking the AA pathway metabolites or injecting DHA has been shown to ameliorate some of the detrimental effects of SCI. However, a combination therapy or a single drug able to modulate both AA and DHA levels would be a more suitable approach to improve outcome after SCI. We now provide evidence that orally administered fenretinide can reduce AA and increase DHA levels after SCI and leads to neuroprotection and enhanced locomotor recovery after SCI. As fenretinide is effective when treatment is delayed for $6 \mathrm{~h}$ after the induction of SCI, and because it is already in use in clinical trials for the treatment of cancer, it is a potentially good candidate for use in the treatment of acute SCI in humans.

\section{References}

Bao F, Chen Y, Dekaban GA, Weaver LC (2004) Early anti-inflammatory treatment reduces lipid peroxidation and protein nitration after spinal cord injury in rats. J Neurochem 88:1335-1344.

Bao F, Dekaban GA, Weaver LC (2005) Anti-CD11d antibody treatment reduces free radical formation and cell death in the injured spinal cord of rats. J Neurochem 94:1361-1373.

Basso DM, Fisher LC, Anderson AJ, Jakeman LB, McTigue DM, Popovich PG (2006) Basso Mouse Scale for locomotion detects differences in recovery after spinal cord injury in five common mouse strains. J Neurotrauma 23:635-659.

Brown WJ, Chambers K, Doody A (2003) Phospholipase A2 (PLA2) enzymes in membrane trafficking: mediators of membrane shape and function. Traffic 4:214-221.

Caughey GE, Pouliot M, Cleland LG, James MJ (1997) Regulation of tumor necrosis factor- $\alpha$ and IL- $1 \beta$ synthesis by thromboxane A2 in nonadherent human monocytes. J Immunol 158:351-358.

Datta PK, Reddy RS, Lianos EA (2001) Effects of all-trans-retinoic acid 
(atRA) on inducible nitric oxide synthase (iNOS) activity and transforming growth factor beta-1 production in experimental anti-GBM antibodymediated glomerulonephritis. Inflammation 25:351-359.

De Sanctis JB (1991) Differences in the enzymatic hydrolysis of a marine lipid concentrate MAXEPA TM in comparison with INTRALIPIDTM. Med Sci Res 19:335-337.

Dheen ST, Jun Y, Yan Z, Tay SS, Ling EA (2005) Retinoic acid inhibits expression of TNF-alpha and iNOS in activated rat microglia. Glia 50:21-31.

Donnelly DJ, Popovich PG (2008) Inflammation and its role in neuroprotection, axonal regeneration and functional recovery after spinal cord injury. Exp Neurol 209:378-388.

Endres S, von Schacky C (1996) n-3 polyunsaturated fatty acids and human cytokine synthesis. Curr Opin Lipidol 7:48-52.

Farooqui AA, Horrocks LA, Farooqui T (2007) Modulation of inflammation in brain: a matter of fat. J Neurochem 101:577-599.

Ferguson AR, Christensen RN, Gensel JC, Miller BA, Sun F, Beattie EC, Bresnahan JC, Beattie MS (2008) Cell death after spinal cord injury is exacerbated by rapid TNF $\alpha$-induced trafficking of GluR2-lacking AMPARs to the plasma membrane. J Neurosci 28:11391-11400.

Floyd RA, Carney JM (1992) Free radical damage to protein and DNA: mechanisms involved and relevant observations on brain undergoing oxidative stress. Ann Neurol 32 [Suppl]:S22-S27.

Folch J, Lees M, Sloane Stanley GH (1957) A simple method for the isolation and purification of total lipides from animal tissues. J Biol Chem 226:497-509.

Formelli F, Cavadini E, Luksch R, Garaventa A, Villani MG, Appierto V, Persiani S (2008) Pharmacokinetics of oral fenretinide in neuroblastoma patients: indications for optimal dose and dosing schedule also with respect to the active metabolite 4-oxo-fenretinide. Cancer Chemother Pharmacol 62:655-665.

Genovese T, Mazzon E, Rossi A, Di Paola R, Cannavò G, Muià C, Crisafulli C, Bramanti P, Sautebin L, Cuzzocrea S (2005) Involvement of 5-lipoxygenase in spinal cord injury. J Neuroimmunol 166:55-64.

Genovese T, Mazzon E, Crisafulli C, Di Paola R, Muià C, Bramanti P, Cuzzocrea $S$ (2006) Immunomodulatory effects of etanercept in an experimental model of spinal cord injury. J Pharmacol Exp Ther 316:1006-1016.

Genovese T, Mazzon E, Crisafulli C, Di Paola R, Muià C, Esposito E, Bramanti P, Cuzzocrea S (2008) TNF-alpha blockage in a mouse model of SCI: evidence for improved outcome. Shock 29:32-41.

Ghasemlou N, Kerr BJ, David S (2005) Tissue displacement and impact force are important contributors to outcome after spinal cord contusion injury. Exp Neurol 196:9-17.

Guilbault C, De Sanctis JB, Wojewodka G, Saeed Z, Lachance C, Skinner TA, Vilela RM, Kubow S, Lands LC, Hajduch M, Matouk E, Radzioch D (2008) Fenretinide corrects newly found ceramide deficiency in cystic fibrosis. Am J Respir Cell Mol Biol 38:47-56.

Guilbault C, Wojewodka G, Saeed Z, Hajduch M, Matouk E, De Sanctis JB, Radzioch D (2009) Cystic fibrosis fatty acid imbalance is linked to ceramide deficiency and corrected by fenretinide. Am J Respir Cell Mol Biol 41:100-106.

Hains BC, Yucra JA, Hulsebosch CE (2001) Reduction of pathological and behavioral deficits following spinal cord contusion injury with the selective cyclooxygenase-2 inhibitor NS-398. J Neurotrauma 18:409-423.

Hall ED, Braughler JM (1986) Role of lipid peroxidation in post-traumatic spinal cord degeneration: a review. Cent Nerv Syst Trauma 3:281-294.

Huang WL, King VR, Curran OE, Dyall SC, Ward RE, Lal N, Priestley JV, Michael-Titus AT (2007) A combination of intravenous and dietary docosahexaenoic acid significantly improves outcome after spinal cord injury. Brain 130:3004-3019.

Jones TB, McDaniel EE, Popovich PG (2005) Inflammatory-mediated injury and repair in the traumatically injured spinal cord. Curr Pharm Des 11:1223-1236.

King VR, Huang WL, Dyall SC, Curran OE, Priestley JV, Michael-Titus AT (2006) Omega-3 fatty acids improve recovery, whereas omega-6 fatty acids worsen outcome, after spinal cord injury in the adult rat. J Neurosci 26:4672-4680.

Kwon BK, Tetzlaff W, Grauer JN, Beiner J, Vaccaro AR (2004) Pathophysiology and pharmacologic treatment of acute spinal cord injury. Spine J $4: 451-464$.
Livak KJ, Schmittgen TD (2001) Analysis of relative gene expression data using real-time quantitative PCR and the 2(-Delta Delta C $(\mathrm{T}))$ Method. Methods 25:402-408.

Lykkesfeldt J (2007) Malonyldialdehyde as a biomarker of oxidative damage to lipids caused by smoking. Clin Chim Acta 380:50-58.

Malone W, Perloff M, Crowell J, Sigman C, Higley H (2003) Fenretinide: a prototype cancer prevention drug. Expert Opin Investig Drugs 12:18291842.

Mehta K, McQueen T, Tucker S, Pandita R, Aggarwal BB (1994) Inhibition by all-trans-retinoic acid of tumor necrosis factor and nitric oxide production by peritoneal macrophages. J Leukoc Biol 55:336-342.

Mey J, J Morassutti D, Brook G, Liu RH, Zhang YP, Koopmans G, McCaffery P (2005) Retinoic acid synthesis by a population of NG2-positive cells in the injured spinal cord. Eur J Neurosci 21:1555-1568.

Montes de Oca M, Loeb E, Torres SH, De Sanctis J, Hernández N, Tálamo C (2008) Peripheral muscle alterations in non-COPD smokers. Chest 133:13-18.

Murakami M, Nakatani Y, Atsumi G, Inoue K, Kudo I (1997) Regulatory functions of phospholipase A2. Crit Rev Immunol 17:225-283.

Niehaus WG Jr, Samuelsson B (1968) Formation of malonulaldehyde from phospholipid arachidonate during microsomal lipid peroxidation. Eur J Biochem 6:126-130.

Ohkawa H, Ohishi N, Yagi K (1979) Assay for lipid peroxides in animal tissues by thiobarbituric acid reaction. Anal Biochem 95:351-358.

Pineau I, Lacroix S (2007) Proinflammatory cytokine synthesis in the injured mouse spinal cord: multiphasic expression pattern and identification of the cell types involved. J Comp Neurol 500:267-285.

Popovich PG, Longbrake EE (2008) Can the immune system be harnessed to repair the CNS? Nat Rev Neurosci 9:481-493.

Resnick DK, Graham SH, Dixon CE, Marion DW (1998) Role of cyclooxygenase 2 in acute spinal cord injury. J Neurotrauma 15:1005-1013.

Ribotta MG, Provencher J, Feraboli-Lohnherr D, Rossignol S, Privat A, Orsal D (2000) Activation of locomotion in adult chronic spinal rats is achieved by transplantation of embryonic raphe cells reinnervating a precise lumbar level. J Neurosci 20:5144-5152.

Rocha PN, Plumb TJ, Coffman TM (2003) Eicosanoids: lipid mediators of inflammation in transplantation. Springer Semin Immunopathol 25:215-227.

Saeed Z, Guilbault C, De Sanctis JB, Henri J, Marion D, St-Arnaud R, Radzioch D (2008) Fenretinide prevents the development of osteoporosis in Cftr-KO mice. J Cyst Fibros 7:222-230.

Sarsilmaz M, Songur A, Ozyurt H, Kuş I, Ozen OA, Ozyurt B, Söğüt S, Akyol O (2003) Potential role of dietary omega-3 essential fatty acids on some oxidant/antioxidant parameters in rats' corpus striatum. Prostaglandins Leukot Essent Fatty Acids 69:253-259.

Saura J, Tusell JM, Serratosa J (2003) High-yield isolation of murine microglia by mild trypsinization. Glia 44:183-189.

Schwab JM, Chiang N, Arita M, Serhan CN (2007) Resolvin E1 and protectin D1 activate inflammation-resolution programmes. Nature 447:869-874.

Serhan CN, Chiang N, Van Dyke TE (2008) Resolving inflammation: dual anti-inflammatory and pro-resolution lipid mediators. Nat Rev Immunol 8:349-361.

Smith WL, Dewitt DL (1996) Prostaglandin endoperoxide H synthases-1 and -2. Adv Immunol 62:167-215.

Torrisi R, Decensi A (2000) Fenretinide and cancer prevention. Curr Oncol Rep 2:263-270.

Xu W, Chi L, Xu R, Ke Y, Luo C, Cai J, Qiu M, Gozal D, Liu R (2005) Increased production of reactive oxygen species contributes to motor neuron death in a compression mouse model of spinal cord injury. Spinal Cord 43:204-213.

Yang L, Blumbergs PC, Jones NR, Manavis J, Sarvestani GT, Ghabriel MN (2004) Early expression and cellular localization of proinflammatory cytokines interleukin-1beta, interleukin-6, and tumor necrosis factor-alpha in human traumatic spinal cord injury. Spine (Phila Pa 1976) 29:966-971.

Yang L, Jones NR, Blumbergs PC, Van Den Heuvel C, Moore EJ, Manavis J, Sarvestani GT, Ghabriel MN (2005) Severity-dependent expression of pro-inflammatory cytokines in traumatic spinal cord injury in the rat. J Clin Neurosci 12:276-284.

Ye YZ, Strong M, Huang ZQ, Beckman JS (1996) Antibodies that recognize nitrotyrosine. Methods Enzymol 269:201-209. 